\title{
As Relações Leste-Oeste e o Terceiro Mundo. Uma Visão sul-americana'
}

Estamos ingressando numa época de dificuldades. Não diminuem as tensões entre as superpotências. As considerações estratégicas, que nunca deixaram de estar presentes, de novo dominam o debate político. A hipótese de um conflito tático na Europa é agora parte dos planos militares. O Afeganistão, o Irã, a Nicaraguá, a Polônia, El Salvador, as Malvinas e o Líbano figuram sucessivamente na primeira página dos jornais. Se o Ocidente industrializado parece em desordem, o Leste não está menos confrontado por problemas. A crise econômica se tornou verdadeiramente global: afeta todas as atividades econômicas e envenena as relações internacionais, comerciais e financeiras. O protecionismo está cada vez mais disseminado. A economia de cada país, independentemente de suas opções políticas e econômicas, vem operando sob severas restrições, enquanto o diálogo multilateral entre países ricos e pobres está virtualmente paralisado.

Diante dessas circunstâncias ameaçadoras, não é surpresa que a política internacional se tenha tornado agitada. O universo do discurso político está dominado pela discórdia e pela acrimônia. A incerteza e a imprevisibilidade estão no ar. Bloqueios econômicos são proclamados e depois suspensos; negociações são iniciadas, interrompidas e depois retomadas. Objetivos irrealistas são acompanhados de exageros retóricos. Fala-se abertamente de intervenções militares.

Uma visão sul-americana ${ }^{2}$ das atuais relações Leste-Oeste necessitaria tomar em consideração todos esses fatores, além de outros. As questões Leste-Oeste permanecem no cerne da vida interna- cional contemporânea; os países e, na verdade, regiões inteiras devem diariamente tratar dessas questões e sobre elas tomar posição.

Não existe uma visão sul-americana unificada quanto à confrontação Leste-Oeste, da mesma forma que não existe, no ocidente, uma avaliação homogênea desse processo. Embora seja crescentemente afetada pela confrontação Leste-Oeste, a América do Sul, no essencial, a ela permanece marginal.

Apenas recentemente comecaram os países sul-americanos a olhar para além de sua própria região e, o que é mais significativo, para além de suas tradicionais relações com os E.U.A. e com a Europa Ocidental. Pode-se afirmar que hoje a América do Sul se preocupa com o panorama global - com a política mundial - , uma vez que seus problemas não mais podem ser resolvidos apenas no nivel regional. Seria, porém, necessário acrescentar que os países sul-americanos reagiram de modo diferenciado aos seus desafios. As naç̃es exportadoras de petróleo ou se associaram à O.P.E.P., - que é uma organização muito difamada - , ou se influenciaram profundamente pelas políticas que a O.P.E.P. adotou, o que Ihes abriu uma janela para o mundo. Alguns países da América do Sul - de diferentes configurações políticas - julgaram oportuno aderir ao movimento não-alinhado. A Colômbia é o mais recente exemplo dessa opção. Embora não trilhe o mesmo caminho, o Brasil mantém excelentes relações com a maioria das nações não-alinhadas e estabeleceu, há quase uma década, firme presença no Oriente Médio e na África, enquanto reforçava diá- 
logo com o Japão e, agora, com o Canadá. Também com os seus vizinhos imediatos, o Brasil incrementou, de forma dramática, o comércio e a cooperação. Outros países sul-americanos, particularmente os menores, devido à escassez de opções, mantiveram política externa ligada quase exclusivamente ao chamado sistema interamericano e a suas relações bilaterais com os EUA.

Também é variado o panorama das relações com a União Soviética. Se se pudesse arriscar generalização, dir-se-ia que a atitude sul-americana predominante é a de manter relações diplomáticas corretas com a U.R.S.S., mas sem muito calor. Há exceções, porém, e o Chile é a maior delas. Como regra, as relações com a U.R.S.S. se estão intensificando, o que era de esperar não só porque seu nível era tradicionalmente muito baixo, mas também porque a União Soviética está procurando, de forma ativa, fazer com que sua presença mundial seja compativel com o seu status de superpotência. Uma das limitações importantes à expansão dessas relações é o temor de que elas possam facilitar o crescimento dos partidos comunistas e grupos a eles afiliados. O comércio entre os países sulamericanose a U.R.S.S. está certamente se tornando mais importante. A União Soviética é de longe o mais importante mercado dos cereais da Argentina, enquanto no ano passado tornou-se o sexto maior cliente comercial do Brasil, cujo principal produto exportado foi a soja. Há anos, os soviéticos vêm vendendo material militar ao Peru.

Esses desenvolvimentos devem ser colocados no contexto de mudanças mais amplas. Não foram os soviéticos os únicos a incrementar sua presença na América do Sul; os europeus ocidentais e os japoneses também fizeram e em escala muito mais ampla. Registraram-se mudanças, sobretudo, na visão que a região tem de si mesma e no modo pelo qual o resto do mundo a vê. Até uns vinte anos atrás, a percepção dominante era a de que a América do Sul, como uma das sub-regiões da América Latina, era parte do hemisfério ocidental e, conseqüentemente, um anexo aos E.U.A.. O conceito de hemisfério ocidental - tão dominante nos anos do pós-guerra - constituía 'retorno' à Doutrina Monroe, já que se baseava não numa parceria real e efetiva nas Américas, mas numa 'presunção hegemôni$\mathrm{ca}^{\prime 3}$. Em última análise, esperava-se que as relações internacionais da região fossem mediadas pelo sistema interamericano, sob a liderança dos E.U.A. Além disso, admitia-se que as divergências com o país-líder seriam resolvidas através de ajustamentos unilaterais por parte dos demais.

O conceito de hemisfério ocidental saiu de moda. Sua superação foi promovida na Europa onde sempre houve pelo menos um interesse laten- te em modificar o arranjo político existente entre os E.U.A. e a América Latina - e também nos próprios E.U.A., depois que o seu envolvimento direto no sudeste asiático absorveu praticamente todas as energias políticas.

A visão monroeista, ao desaparecer, não foi substituída por sua alternativa histórica, o antigo sonho boliviano de uma América hispânica unida, sonho que em sua versão modernizada poderia ter atraído o Brasil e talvez os países caribenhos, mas que seguramente excluiria os E.U.A.. Não mais havia condições para essa opção, pois a América Latina, região até então poupada do turbilhão da vida internacional, foi atirada ao caldeirão fervente da política mundial.

É simples a razão para a mudança no papel internacional da América Latina. Os E.U.A. não mais estão em condições de suprir a região com os insumos - políticos, econômicos e outros - que costumavam prover ou tornar disponíveis. Nem é a economia norte-americana capaz de absorver a mesma proporção de mercadorias da região. Os países da América Latina devem procurar no mundo todo, do Japão à Europa, do Oriente Médio à África, os bens e serviços, assim como a tecnologia, os recursos e os mercados de que hoje necessitam. O conceito de hemisfério ocidental foi abandonado porque reflete compromisso ou relação especial que não mais tem apoio tanto em Washington, quanto em muitas capitaislatino-americanas.

Neste ponto, desejaria apresentar três comentários sobrea questão Leste-Oeste propriamente dita.

Em primeiro lugar, deve-se ter presente que o Leste é o Leste, e o Ocidente é o Ocidente. Isto é, a natureza política dos dois blocos é, ou deveria ser, diferente. Os tipos de arregimentação política que fazem parte do cotidiano do Leste não são realmente permissíveis no Ocidente e, se permitidos, são considerados claros desvios do corpo central dos ideais ocidentais. Na realidade, o pluralismo é regra no Ocidente, pluralismo nas relações entre cidadãos, assim como entre Estados. O pluralismo é, talvez, a maior virtude ocidental. Embora freqüentemente obrigue à tarefa árdua e prolongada de coordenação de posições divergentes, o pluralismo assegura ao Ocidente flexibilidade e capacidade de resistência política.

Em segundo lugar, observaria que já é legítimo especular sobre o papel da América Latina na confrontação Leste-Oeste, uma vez que a luta pelo Terceiro Mundo, juntamente com outras questões, é tida, hoje, como um aspecto daquela confrontação e que a América Latina, por sua vez, é amplamente considerada área do Terceiro Mundo. Deve-se, po- 
rém, ter sempre presentes as peculiaridades da história da América Latina, bem como sua proximidade geográfica dos E.U.A., fatores que certamente condicionam o status internacional da região, particularmente quando tomada como elemento, ainda que marginal, nas disputas Leste-Oeste.

$O$ terceiro comentário diz respeito à definição geográfica e política do Leste e do Ocidente. Ao final da guerra fria, já se podia afirmar que o Leste é formado pela União Soviética e os demais países da Europa Oriental (salvo lugoslávia e Albânia). A China já obtivera sua independência de Moscou, enquanto nos outros países do Terceiro Mundo, como Vietname, Angola e Etiópia, que durante as décadas dos sessenta e dos setenta foram colocados sob a influência soviética, aplicavam-se regras próprias, por duas razões principais:

1. essas áreas não são contíguas à União Soviética, o que em última análise diminui a influência de Moscou sobre elas. Cuba - por ser totalmente exposta aos E.U.A. - por ser, na prática, contígua a esta superpotência - é, paradoxalmente, um caso especial de vulnerabilidade à União Soviética;

2. esses países do Terceiro Mundo, apesar de suas opções socialistas, pertencem, diferentemente da Europa, a áreas sob efetiva disputa entre o Leste e o Oeste. Salvo em 'cenários' de guerra total, ou quase, ninguém realmente espera mudança fundamental no equilíbrio de forças na Europa, enquanto no Terceiro Mundo muitas situacões políticomilitares permanecem instáveis e podem ser modificadas sem aqueles'cenários'.

Se considerarmos a política dentro do bloco oriental, dois fatores devem ser mencionados:

1. o papel predominante desempenhado pela União Soviética. A oposição só pode ser expressa por meio da retirada do bloco, uma opção que a China exerceu, pagando um preço, mas que devido às realidades militares não parece ter outros tomadores nestemomento;

2. a hegemonia soviética não parece funcionar de forma dinâmica, pois não favorece - e talvez nem o permita - o ajustamento político no tempo. Pelo contrário, parece almejar a manutenção estática da relação de preponderância, negando dessa forma o fenômeno universal da difusão do poder e contendo a autonomia dos demais membros do bloco oriental.

Estou pessoalmente convencido de que os acontecimentos na Polônia significam essencialmente que o Leste está passando por severa crise político-ideológica e que o Ocidente cometeu um erro ao permitir que as atenções mundiais se desviassem dessa situação. Mesmo no período anterior ao 13 de dezembro de 1981 , já se notava falta de percepção no Ocidente, exceto talvez na Alemanha Federal, sobre o que se estava acontecendo na Polônia. Na prática, o desentendimento no Ocidente sobre como reagir aos acontecimentose, ainda mais, a troca de recriminações com a União Soviética levaram à avaliação errônea de que o problema polonês era, mais do que uma crise no Leste, uma questão Leste-Oeste, ou entrea U.R.S.S. eos E.U.A. Como a confirmar esta última percepção, a questão polonesa está, agora, sendo tratada como episódio da Guerra Fria. Não estou certo, porém, de que a instabilidade no Leste seja necessariamente de interesse do Ocidente como um todo.

Como a liberalização da Polônia estava ligada, embora frouxamente, ao processo de déten'e na Europa, é difícil escapar à hipótese de que a normalização das relações Leste-Oeste colocaria ao Leste o desafio do ideal ocidental do pluralismo. Este desafio é potencialmente perigoso para o Leste e para as relações Leste-Oeste, o que configura um limite objetivo ao processo de déten'e.

Por outro lado, tendo em vista as atuais realidades tecnológicas e desenvolvimentos políticos, parece pouco crivel que a União Soviética e os outros países do Leste europeu consigam manter-se imunes ao processo de mudança política. Á medida em que as sociedades do Leste se tornam mais complexas, suas economias se diversificam e novos grupos sociais são chamados a participar da administração da produção e do consumo, assim como da inovação tecnológica criativa, é cada vez mais difícil isolar tais grupos das influências não controladas pelo sistema político unipartidário.

Seria excessivamente fatalista supor que é inevitável a estagnação política no Leste, sobretudo porque a mudança pode ser um meio de evitar dificuldades na política interna. Não penso que estejamos assistindo ao fim do sistema socialista e que isso ocorrerá quer por convulsão, quer por evolução pacífica em direção a um sistema aparentado com o capitalismo. Não creio ser correto que a melhor opção ocidental seja a de aumentar a pressão sobre o Leste com o fito de acelerar qualquer desses dois possíveis processos.

Examinemos, agora, a definição de Ocidente, neste final de século.

Essa é, necessariamente, uma questão complexa. Em conseqüência de várias levas de expansão marítima, a civilização ocidental se tornou mundial, ganhou amplitude verdadeiramente universal. Com o tempo, as idéias de Ocidente e de civilização se associaram. Padrões culturais não-ocidentais foram desvalorizados e começaram a ser tratados como 'locais' ou 'periféricos', com a implicação de que o 
que ocorria no mundo desenvolvido era 'universal' ou 'central' , enquanto os acontecimentos nas áreas economicamente retardatárias só poderiam ter significação circunscrita ou marginal.

Ressalte-se que a modernização dessas áreas era considerada possível. Uma vez aceitas como civilizadas, essas sociedades tinham maiores probabilidades de serem tratadas como países ocidentais 'honorários'. Essa forma de modernização dependia da importação de técnicas e da reprodução de padrões culturais ocidentais. Esse foi o caminho originalmente tomado pela Rússia e Japão.

Com o nosso século, contudo, uma visão menos otimista parece afirmar-se. A revolução comunista, o fascismo, a depressão econômica, tudo indica a existência de problemas no Ocidente.

Depois da Segunda Guerra Mundial, a idéia de 'civilização ocidental' parece contrair-se e confinarse a conceito muito menos abrangente de 'civilização industrial' limitado ao círculo estreito das democracias industriais. Nessa abordagem não se pretende que a idéia de Ocidente seja realmente universal, mas que se localize nos limites da O.C.D.E. (Europa Ocidental, E.U.A., Canadáe Japão).

Torna-se crescentemente difícil para os países em desenvolvimento alcançar níveis de progresso tecnológico e qualidade de vida comparáveis aos desfrutados pelos países ocidentais desenvolvidos. Isto pode ser verdade para as nações em desenvolvimento como um grupo e, mesmo, individualmente, o que significaria que o caminho anteriormente tomado pela Rússia e Japão parece agora bloqueado.

Nessas circunstâncias, a melhor maneira de defender a civilização ocidental - e, na verdade, a própria civilização - seria promover a concentração de altos niveis de bem-estar econômico, paz sociale tranqüilidade política em alguns poucos países ocidentais, enquanto se daria tratamento paliativo aos males mais agudos do Terceiro Mundo. Esse enfoque leva naturalmente ao congelamento do poder mundial ${ }^{4}$ eà détente seletiva na Europa.

Outro modo de empobrecer a idéia ocidental é transformá-la num instrumento da luta políticoideológica contra o bloco soviético, e reduzir uma idéia densa e poderosa a um simples anticomunismo ou anti-sovietismo. No nivel militar, que é sempre privilegiado quando a política é confundida com a luta, a OTAN se transformaria na expressão mais perfeita e acabada do Ocidente.

Esta é uma simplificação que gera numerosas distorções. Como organização militar, a OTAN é concebida para a luta e destruição do inimigo. Conseqüentemente, entre as opções disponíveis para a interação com os soviéticos, a OTAN tende a sele- cionar as mais drásticas, ainda que relativamente menos prováveis. Como expresso pela OTAN, o Ocidente mantém dimensões militares, embora perca boa parte de sua capacidade de inventar novas formas de interação com a União Soviética. A crescente militarização do discurso político ocidental cria inflexibilidade e, em última análise, torna mais fácil o caminho para os adversários do Ocidente, pois lhes cede terreno para o crescimento de sua influência política. Além disso, a OTAN, de todas as instituições internacionais, é aquela em que os E.U.A. melhor mantiveram supremacia. Sua escoIha para expressar a idéia ocidental, portanto, acentua o poder dos E.U.A. dentro do Ocidente lou, mais precisamente, em relação à Europa Ocidental) .

O empobrecimento da idéia ocidental, desde a Segunda Guerra Mundial, a coloca em perigo. Por si sós, as instituições estabelecidas pelo Ocidente para administrar a aliança militar e a cooperação econômica entre os países altamente industrializados e democráticos, quais sejam a OTAN e O.C.D.E., são incapazes de expressar todas as potencialidades da idéia ocidental. Lamentavelmente, porém, o debate político no Ocidente não parece ir muito além da política da OTAN e da O.C.D.E.. Aí se localiza provavelmente uma das principais raízes do que já se percebe como importante crise do Ocidente. Uma visão mais ampla seria necessária para que o Ocidente possa dar resposta eficaz à União Soviética.

Politicamente, os limites dessa crise já estão bastante claros. O debate no seio do Ocidente industrializado é cada vez maior, e seu tom se deteriora. Algumas das premissas da Aliança Atlântica estão sendo mais questionadas. Anos de hesitação nos E.U.A. foram seguidos por nova fase de afirmação, que toca às raias do unilateralismo. É duvidoso se as atuais políticas norte-americanas com relação ao resto do Ocidente industrializado constituem esforço para manter o status quo e mesmo para voltar a uma era anterior de hegemonia, ou se serão mais criativas e aceitarão a crescente importância dos países da Europa Ocidental na política mundial. Mas isso só ocorrerá se esses países demonstrarem capacidade de equilibrar sua dedicação à détente na Europa com o seu maior envolvimento em outras áreas.

Não é segredo que a Europa Ocidental, colhida pelos ventos tempestuosos da confrontação Leste-Oeste e pela crise econômica mundial, parece um tanto insegura de si mesma. Mesmo a identidade dos países europeus está em mudança. Freqüentemente os governos europeus falam por si mesmos, mas às vezes assumem identidade européia comum, cujos limites não são inteiramente claros: além disso, a flexibilidade que demonstram ao tratar de questões relativas ao Terceiro Mundo e ao diálo- 
go norte-americano, parece predicada na presunção de que, em último caso, os E.U.A. se manterão inflexíveis.

Em resumo, há real crise no Ocidente e a política dentro da OTAN e da O.C.D.E. não é capaz de explicá-la, nem muito menos de abrir caminhos para solução e de prover os insumos políticos necessários à uma resposta adequada à política mundial da União Soviética.

A América Latina (e a América do Sul) é parte do Terceiro Mundo. Se há diferenças marcantes entre a América do Sul e as demais áreas do Terceiro Mundo, há também afinidades importantes - a geografia, o clima, a composição étnica, a história da interação com o Ocidente, os atuais problemas econômicos - que unem aquele vasto grupo denações. A heterogeneidade é, portanto, um fato, mas não impede a América Latina, a África e Ásia de serem consideradosmembros do Terceiro Mundo.

Observaria, ainda, que ser considerado como país do Terceiro Mundo tem significados diferentes na Europa e nos E.U.A.. Na Europa, a idéia de Terceiro Mundo ainda pode gerar simpatias, mas nos E.U.A. ela é usualmente associada a experiências desagradáveis no Sudēste Asiático, no Oriente Médio e em outras regiões.

A América do Sul é região muito complexa; suas similaridades são enganadoras. Cada país enfrenta seus próprios problemas internos, que vão desde, em alguns casos, a agitação popular até, em outros, o funcionamento normal dos processos democráticos. Mesmo quando as dificuldades recebem os rótulos idênticos, uma simples visita às capitais desses países permite identificar sua diversidade. Conseqüentemente, a tentação sempre presente de simplificar a realidade deve ser combatida; da mesma forma, é inadequado afirmar contradições de tipo maniqueísta ou empregar a retórica fácil. Por exemplo, não é realista supor que a vida política latino-americana vá obedecer a um único padrão, seja democrático, seja autoritário; na região como um todo e mesmo em cada país sempre haverá combinação complexa dessas duas tendências.

Não é provável que, no futuro previsível, os regimes políticos na América do Sul se tornem homogêneos. Isto não aconteceu no passado e não há razão para pensar que venha a ocorrer no futuro. A América do Sul deve ser tratada como ela é e não como presumivelmente deveria ser.

Os vínculos históricos entre os países sulamericanos sempre foram de modo geral débeis. Na década dos setenta, todavia, essa situação começou a mudar. A crise das ilhas Malvinas demonstrou que existe espaço para aumentar a coordenação entre os países da região. Quanto ao Brasil, nosso en- volvimento com os países vizinhos é cada vez maior e mais promissor. A política e a economia, assim como a literatura e os esportes dos países sulamericanos estão se tornando parte do cotidiano brasileiro. No ano passado, o Brasil exportou mais mercadorias para a América Latina do que para os E.U.A., culminando um processo já iniciado há uns vinte anos. A questão agora - com a determinação da situação internacional, que prejudica de forma desproporcional a América Latina - é saber se esse processo continuará a desenvolver-se ou se será paralisado e revertido.

O reforço da solidariedade e a busca da integração e unidade permanecem objetivo sério para muitos países sul-americanos. Essa solidariedade e essa unidade, no entanto, deverão ser construídas com base em nossas diversidades. Nossa unidade - essencial até para as negociações com o mundo industrializado - dependerá da aceitação da diversidade, como elemento permanente dos processos políticos da região.

A América Latina é vulnerável e suas relações com o mundo desenvolvido são, ainda, desequilibradas. Dependem de considerações, métodos e valores essencialmente estranhos à região. Para que esse relacionamento possa tornar-se mais equilibrado, a participação da América Latina nele deve ser gradualmente fortalecida.

Com a deterioração contínua da situação internacional, os países sul-americanos estão se vendo mais e mais obrigados a tomar posições diante das questões Leste-Oeste. Parece claro que, nos problemas relativos ao equilíbrio estratégico ou aos interesses da Europa Ocidental, as superpotências se sentem compelidas a agir dentro dos limites da moderação. São exemplos dessa prática a continuação, apesar de todos os obstáculos, das negociações sobre armamentos, a cautela recíproca no tratamento da crise polonesa, e o comércio com o Leste, que persiste apesar de sanções ocasionais e seletivas por parte dos E.U.A..

Tendo em vista o equilíbrio estratégico e o avanço do processo de estabilização política na Europa, a confrontação crescentemente se transfere para o Terceiro Mundo, no qual as tensões regionais atraem de forma inexorável a intervenção das superpotências. Em conseqüência, os processos políticos do Terceiro Mundo, já de si complexos, ganham nova e perturbadora dimensão.

O Terceiro Mundo, como resultado, é freqüentemente comparado a um tabuleiro de xadrez no qual os E.U.A. e a U.R.S.S. testam suas habilidades e firmeza e agem como fatores de desestabilização. A intensificação da rivalidade entre Washington e Moscou soma-se à turbulência daquela vasta 
área. As duas superpotências têm importante responsabilidade na exacerbação das crises engendradas pelas circunstâncias locais. A perspectiva de détente ou de confrontação se tornou a mais importante das questões políticas no Terceiro Mundo.

Tal ocorre numa fase em que não mais se registram coincidências automáticas entre as políticas externas dos E.U.A. e das maiores nações sulamericanas Embora os E.U.A. retenham certas formas de preponderância regional, a América do Sul como um todo não se sente obrigada a seguir de forma inquestionável a linha de política externa adotadapor Washington.

Nos anos setenta e no início dos oitenta, criouse um espaço político que permite a certos países latino-americanos assumir posições próprias em questões específicas no plano global. Por outro lado, diferentes situações latino-americanas têm sido tratadas como episódios da competição LesteOeste. Tais situações, embora engendradas localmente, foram e continuam a ser exploradas no contexto Leste-Oeste. De certa forma, isso aconteceu no passado em Cuba e no Chile, e a atual crise na América Central pode ser o mais recente desses episódios.

Deve-se acentuar, entretanto, que a América dificilmente pode inserir-se no plano da confrontação militar Leste-Oeste. Na realidade, Cuba é o único país latino-americano no qual a União Soviética tem presença militar direta e, mesmo assim, os soviéticos estão limitados pelo entendimento de 1962 com os norte-americanos. Apenas as crises entre os países latino-americanos, ou dentro de um deles, poderiam atrair a confrontação Leste-Oeste para a região. Além disso, a confrontação afeta a América Latina na medida em que perturba a vida internacional, ameaçando até o diálogo Sul-Sul, pois as políticas de bloco estimulam a criação de barreiras entre os paises em desenvolvimento.

Não se deve esquecer que a América Latina é também parte do Ocidente, o que vem ilustrar a tese de que o Ocidente fiel a seu próprio patrimônio histórico - não pode reduzir-se ao mundo das nações democráticas e industrializadas, isto é, ao Primeiro Mundo.

Apesar de seus equívocos, as nações da América do Sul permanecem devotadas às formas liberais de Governo e à democracia política. Os regimes autoritários, qualquer que seja sua duração no tempo, são quase sempre encarados como 'desvios' da normalidade. Na política internacional, esses países continuam a favorecer as idéias e princípios ocidentais, como o pluralismo, a igualdade soberana dos Estados e a autodeterminação. Consideramos, na América do Sul, que quando o colonialismo e o ra- cismo aparecem no Ocidente constituem aberrações que não correspondem aos ideais ocidentais.

Note-se que a América do Sul é parte do Ocidente por direito próprio ${ }^{5}$. Neste ponto, nenhuma concessão por parte dos países industrializados se faz necessária, embora seja claro que se tais países estiverem realmente interessados em responder de forma efetiva aos desafios do Leste terão que aceitar a localização específica da América do Sul no espectro da política mundial.

Embora integrem o Ocidente, as nações sulamericanas são e continuarão a ser diferentes dos países industrializados ocidentais. A América do Sul tem sua própria vida cultural, que incorpora elementos não-ocidentais muito importantes. Existe, dessa forma, certa distância entre a América do Sul e o resto do Ocidente, distância que faculta uma abordagem crítica na consideração dos problemas globais do Ocidente e das relações Leste-Oeste, em particular.

Em conclusão, apresentaria, como solicitado, algumas observações de cunho político relacionadas com o que precede:

Primeiro - O Ocidente deveria redefinir-se de modo abrangente. O Ocidente não se circunscreve aos países membros da OTAN ou, no máximo, da O.C.D.E. Deve o Ocidente ir além do mundo industrializado e incorporar os países do Sul, especialmente da América do Sul, que por suas crenças filosóficas, tradições históricas, aspirações políticas e estruturas econômicas são parte do mundo ocidental. Como agregado de nações, o Ocidente é seguramente mais amplo do que o Primeiro Mundo

Segundo - Parcerias genuínas devem ser estabelecidas dentro do Ocidente ampliado. Os países do sul, com a América Latina à frente, devem ter acesso aos mecanismos decisórios ocidentais. O Ocidente deve criar espaço não só para as posições dos países desenvolvidos que, no final das contas, são os principais beneficiários do sistema mundial, mas também para os interesses dos países que não se beneficiam de forma eqüitativa da presente ordem econômica internacional e que, ao mesmo tempo, partilham da mesma cultura com o Ocidente.

Terceiro - O Ocidente deve empreender um esforço concertado para recuperar a confiança do Terceiro Mundo. O Ocidente industrializado deve facilitar o acesso dos países pobres ao desenvolvimento; esse é o modo de assisti-los na recuperação de sua confiança nos modelos e métodos ocidentais. (As nações do Terceiro Mundo terão também que fazer a sua parte: sob condições apropriadas, deverão superar a visão tradicional que atribui ao Ocidente tudo o que há de mau em suas relações in- 
ternacionais. À medida em que o Ocidente industrializado se distancia do colonialismo e do neocolonialismo e toma a iniciativa com vistas ao estabelecimento de verdadeiras parcerias com o Terceiro Mundo, a reciprocidade se fará necessária.) A mais longo prazo, deve ser buscada a convergência de interesses entre o Ocidente eo Terceiro Mundo, 0 que, porém, só se tornará possível se o Ocidente se convencer de que o Terceiro Mundo não é mero objeto de sua ação ou uma simples periferia de um centro industrializado todo-poderoso. A era do paternalismo está se encerrando rapidamente.

Quarto - O Ocidente precisa aceitar que o diálogo Norte-Sul é importante e que o impasse é revelador de muitas das deficiências teóricas e práticas do ideal ocidental. A falência do diálogo NorteSul significaria que também faliu a visão mais ampla do Ocidente, e que estaremos condenados à confrontação Norte-Sul.

Finalmente, o esforço ocidental para evitar a expansão soviética no Terceiro Mundo deve ter presente o que precede. Não deve levar à imposição de alinhamentos rígidos ou à articulação de blocos sob patrocínio unilateral. Os problemas criados pela U.R.S.S. devem ser tratados diretamente com Moscou e as crises regionais devem ser vistas à luz de suas próprias peculiaridades e das causas locais de tensão. A intervenção direta deve ser evitada, pois uma coisa parece certa: 0 Ocidente não redimirá errosno Terceiro Mundo por meio da ação militar.

\section{Notas}

1. Preparado para a reunião de 1982 da Atlantic Conference (St. Croix, V.I, E.U.A., de 4 a 7 de novembro de 1982)

2. A pedido dos organizadores da Atlantic Conference, o ângulo de visão do presente estudo é sul-americano. $O$ autor teria preferido tratar o tema de uma abordagem latino-americana.

3. A expressão "presunção hegemônica" é da autoria de Abrahm F. Lowenthal, em The United States and Latin America: Ending the Hegemonic Presumption (Foreign Affairs, outubro de 1976).

4. A teoria do congelamento do poder mundial foi originalmente proposta pelo falecido Embaixador J.A. de Araujo Castro.

5. Aplicada ao Brasil, essa observação foi feita pelo professor Hélio Jaguaribe de Mattos. 